\title{
PENGEMBANGAN KURIKULUM \\ BIDANG STUDI PENDIDIKAN AGAMA ISLAM PADA \\ PROGRAM AKSELERASI DI SMAN 5 SURABAYA
}

\author{
Ishmatun Nihayah \\ Dosen Institut Pesantren KH Abdul Chalim Mojokerto \\ ishmahnihayah@gmail.com
}

\begin{abstract}
Abstrak
Pada penelitian ini kami fokus pada dua hal, pertama pelaksanaan akselerasi di SMAN 5 Surabaya. Ke dua, pengembangan kurikulum bidang studi Pendidikan Agama Islam pada program akselerasi di SMAN 5 Surabaya. Untuk memperoleh jawaban dari kedua fokus penelitian, kami menggunakan penelitian deskriptif kualitatif. Sumber data ini menggunakan trianggulasi, yakni dokumentasi, observasi dan wawancara. Teknik dokumentasi digunakan untuk memperoleh data tentang dokumen I dan dokumen II mengenai kurikulum, kemudian teknik observasi dan wawancara kami gunakan untuk mencarai data tentang situasi, kondisi, keadaan sekolah (mulai dari lingkungan, aktifitas siswa, perilaku siswa, proses pembelajaran dan lain-lain).

Kata Kunci: Pengembangan Kurikulum, Program Akselerasi, Pendidikan Agama Islam

Abstract

In this study we focus on two things; the first is the implementation of acceleration program in SMAN 5 Surabaya, the second is the curriculum development in the field of study of Islamic Religion in the acceleration program in SMAN 5 Surabaya. To obtain answers from both research focuses, we use qualitative descriptive method. The data source applies triangulation, namely documentation, observation and interviews. Documentation techniques are used to obtain data about documents I and document II, then we use observation and interview techniques to find the data about the situation, conditions, and circumstances of the school (starting from the environment, student activities, student behavior, learning process, etc.).
\end{abstract}

Keywords: curriculum development, acceleration program, Islamic Education

Nazhruna: Jurnal Pendidikan Islam

Vol. 1 No 2 Agustus 2018. Issn: 2614-8013. Hal. 312-323 


\section{Pendahuluan}

Pada saat ini khususnya di Indonesia sudah lumayan banyak sekolah yang mengadakan kelas akselerasi, baik dari sekolah milik swasta maupun sekolah milik pemerintah. Misalnya di SMA Negeri 5 Surabaya, SMP Negeri 3 Surabaya, SMA Negeri 1 Surabaya, Madrasah Aliyah Amanatul Ummah dan masih banyak lagi.

Akselerasi berasal dari Bahasa Inggris acceleration yang berarti percepatan. Sedangkan akselerasi dalam pengertian istilah menurut Colangelo dan Hawadi menyebutkan bahwa istilah akselerasi menunjukkan pada pelayanan yang diberikan (Service Delivery) dan kurikulum yang disampaikan (Curriculum Delivery). Sebagai model pelayanan, akselerasi dapat diartikan sebagai model layanan pembelajaran dengan cara lompat kelas, misalnya bagi siswa yang memiliki kemampuan tinggi diberi kesempatan untuk mengikuti pelajaran pada kelas yang lebih tinggi. ${ }^{1}$

Menurut Sutratinah Tirtonegoro, percepatan (acceleration) adalah cara penanganan anak super normal dengan memperbolehkan naik kelas secara meloncat atau menyelesaikan program reguler di dalam jangka waktu yang lebih singkat. ${ }^{2}$ Hal senada juga disampaikan oleh Ulya Latifah Lubis dan Hawadi yang mendefinisikan istilah akselerasi sebagai progaram pengayanan yang diberikan kepada siswa dengan tingkat keberbakatan tinggi agar dapat menyelesaikan masa belajarnya lebih cepat dari siswa yang lain (program reguler). ${ }^{3}$

Dari beberapa pengertian tersebut dapat disimpulkan bahwa program akselerasi adalah program pelayanan yang diberikan kepada siswa dengan tingkat keberbakatan tinggi agar dapat meyelesaikan masa belajarnya lebih cepat dari siswa yang lain (program reguler), tentunya dengan menggunakan alat yang disebut kurikulum, dan metode yang tepat yaitu

\footnotetext{
${ }^{1}$ Ngalim Purwanto, Psikologi Pendidikan, (Bandung: Remaja Rosdakarya, 1992), 107. Syaiful Bahri Djamarah, Psikologi Belajar, (Jakarta: Rineka Cipta, 2008), 175 - 190

2 Sutratinah Tirtonegoro, Anak Supernormal dan Program Pendidikannya, (Yogyakarta: Bumi Aksara, 2001), 10

${ }^{3}$ Reni Hawadi Akbara, Keberbakatan Intelektual, (Jakarta: Grasindo: 2001), vii
} 
dengan menganalisis materi pelajaran dengan materi yang essensial dan kurang essensial.

Dengan demikian, program akselerasi ini membutuhkan kurikulum yang disesuaikan dengan waktu yang lebih cepat untuk menguasai materi pelajaran. Dengan kata lain, siswa yang seharusnya menyelesaikan studi SMA dalam tiga tahun diprogram untuk dapat menyelesaikan materi kurikulum (yang telah didiferesiasi) dalam waktu dua tahun.

Program akselerasi ini diselenggarakan berdasarkan pendapat bahwa siswa yang memiliki kemampuan dan kecerdasan yang luar biasa berhak memperoleh perhatian khusus. Karena itu sebagai hak mereka, mereka berhak mendapatkan perlakuan sesuai dengan bakat minat dan kemampuannya, mereka berhak mengikuti program pendidikan atas dasar pendidikan berkelanjutan, baik untuk mengembangkan kemampuan diri maupun untuk memperoleh pendidikan lebih awal dari waktu yang ditentuan.

Walaupun kelas akselerasi ini masih menuai pro dan kontra, namun kelas ini masih dipandang sebagai kelas yang baik sebagai kelas terobosan bagi siswa berbakat akademik. Misalnya, dalam melaksanakan program akselerasi, mempunyai beberapa faktor penghambat dan pendukung. Diantara faktor penghambatnya adalah minimnya standar kompetensi dan keprofesionalan guru, siswa cenderung meremehkan nilai program normatif (mata pelajaran agama), minimnya penguasaan guru dalam menggunakan media pembelajaran. Guru kurang kreatif dalam mengembangkan metode pembelajaran, serta alokasi waktu yang sedikit untuk mata pelajaran Pendidikan Agama Islam.

Program akselerasi atau program percepatan merupakan suatu program untuk peserta didik yang memiliki tingkat kecerdasan luar biasa atau dengan kata lain program untuk mempercepat masa studi bagi peserta didik yang memiliki tingkat kecerdasan tinggi yang berhak untuk mendapat perhatian khusus agar dipacu perkembangan prestasi dan bakatnya. Misalnya SD atau Madrasah Ibtidaiyah diselesaikan dalam 4 tahun, SMP atau Madrasah Tsanawiyah dalam 2 tahun begitu juga dengan SMA yang setara dengan Madrasah Aliyah. Dengan kata yang lebih klise, menyipakan 'pendekar' calon pemimpin masa depan. 
Jaminan Pemerintah terhadap pelayanan pendidikan bagi anak berbakat akademik (intelektual) atau lazim disebut peserta didik yang memiliki potensi potensi kecerdasan dan bakat istimewa dinyatakan dalam Undang-Undang No. 20 Tahun 2003 tentang Sistem Pendidikan Nasional. Bab IV pasal 5 ayat (2) yang berunyi: "Warga Negara yang memiliki kelainan fisik, emosional, mental, intelektual dan / sosial berhak memperoleh pendidikan khusus". (UU No.20). ${ }^{4}$

Perlu diketahui bahwa kurikulum pendidikan di Indonesia saat ini banyak melakukan perubahan, termasuk dalam pengembangan kurikulumnya. Sepanjang sejarah telah tercatat beberapa kurikulum yang diterapkan di Indonesia, diantaranya; kurikulum tahun 1968 (subject matter curriculum), lalu disempurnakan menjadi kurikulum tahun 1975 yang memiliki ciri-ciri correlated curriculum, Kemudian disempurnakan menjadi Kurikulum tahun 1984, kurikulum ini berlangsung kurang lebih 10 tahun. ${ }^{5}$

Sekolah yang kami teliti pada tahun 2013 menggunakan kurikulum KTSP. Kurikulum yang ada pada kelas akselerasi berbeda dengan kurikulum pada umumnya, walaupun materi dan pokok-pokok bahasan di dalamnya adalah sama. Disamping itu dengan waktu yang lebih singkat, diharuskan ada pengembangan kurikulum. Inilah yang menjadikan tantangan bagi guru untuk mengembangkan kurikulumnya sesuai dengan materi pelajaran, dalam hal ini adalah materi Pendidikan Agama Islam. Bagaimana mengembangkan kurikulum bidan studi Pendidikan Agama Islam tersebut?. Oleh karena itu kurikulum yang diberikan akan berbeda dengan kelas reguler, tetapi harus tetap dapat mengembangkan kurikulum Pendidikan Agama Islam tersebut. Karena kelas akselerasi adalah kelas yang ditempuh dalam tempo yang lebih singkat dibandingkan dengan kelas reguler.

Sekolah didirikan untuk anak-anak, untuk membimbing mereka dalam pertumbuhan dan perkembangannya agar menjadi manusia yang sanggup menghadapi masalah-masalah dalam hidupnya sebagai orang dewasa sesuai dengan tujuan dan cita-cita negara. Oleh karena itu faktor

\footnotetext{
${ }^{4}$ Undang-Undang No. 20 Tahun 2003 tentang Sistem Pendidikan Nasional

${ }^{5}$ Hendyat Soetopo dan Wasty Soemanto, Pembinaan dan Pengembangan Kurikulum, (Jakarta: Bumi Aksara, 1993), 5
} 
anak tadi merupakan hal yang sangat penting dalam menggunakan dan mengembangkan kurikulum (S. Nasution, 1986). ${ }^{6}$

Setiap anak pasti berbeda disebabkan perbedaan pembawaan dan lingkungan. Ada yang tingkat intelektualnya tinggi ada yang sedang ada pula yang rendah, seperti yang telah dijelaskan di atas, bahwa adanya perbedaan tersebut, akhirnya dibuat program akselerasi bagi siswa yang berkemampuan tinggi. Perbedaan program tersebut, mengakibatkan perbedaan kurikulum serta cara mengembangkannya.

\section{Hasil Dan Pembahasan}

Dari penelitian yang berhasil kami lakukan terhadap program akselerasi, kami menemukan beberapa hal terkait dengan dokumen 1 dan dokumen 2. Dokumen 1 terdiri atas berkas-berkas yang terkait dengan pengembangan kurikulum secara umum. Dan dokumen 2 terkait dengan pembelajaran yang terdiri atas perencanaan pembelajaran, aplikasi pembelajaran dan evaluasi pembelajaran.

Dari dokumen 1, kami memperoleh data bahwa dalam mengembangkan kurikulum terlebih dahulu diadakan Tim pengembang kurikulum. Tim tersebut terdiri dari, Kepala Sekolah, Guru dan Komite Sekolah. Kurikulum disusun sangat rapi, mulai landasan pengembangan kurikulum, Tujuan Pengembangan kurikulum, prinsip dasar pengembangan kurikulum, Tujuan pendidikan dan struktur muatan kurikulum.

Di sekolah yang kami teliti, program akselerasi diproyeksikan untuk program Ilmu Alam karena kebanyakan siiwa yang mampu IQ nya adalah yang jurusan IPA. Standar IQ Minimal Siswa Akselerasi

\begin{tabular}{llllllll}
\hline NO & \multicolumn{3}{c}{ JENIS TES } & & \multicolumn{2}{c}{ IQ MINIMAL } \\
\hline 1. & Culture fair intelligence test skala & 2A/2B/ & Very & Superior = \\
& $(\mathrm{SD} / \mathrm{MI})$ & & & 130 & \\
& & & & & \\
& Culture fair intelligence test skala & 2A/2B/ & Very & Superior = \\
& $(\mathrm{SMP} / \mathrm{Mts})$ & & & 130 & \\
\hline
\end{tabular}

${ }^{6}$ S. Nasution, Asas-Asas Kurikulum, (Bandung: Jemmars, 1986), 88. 
Vol. 1 Nomer 22018

\begin{tabular}{|c|c|c|c|c|c|}
\hline & $\begin{array}{l}\text { Culture fair intelligence test skala } \\
\text { (SMA/MA) }\end{array}$ & $2 \mathrm{~A} / 2 \mathrm{~B} /$ & $\begin{array}{l}\text { Very } \\
130\end{array}$ & Superior & $=$ \\
\hline 2. & Colour Progressive matrix & & Grade & I percentil & 95 \\
\hline 3. & Stabford Binet Test & & $\begin{array}{l}\text { Very } \\
140\end{array}$ & Superior & $=$ \\
\hline \multirow[t]{3}{*}{4.} & Wechsler Intelligences Scale for Children & $(\mathrm{SD} / \mathrm{MI})$ & $\begin{array}{l}\text { Very } \\
130\end{array}$ & Superior & $=$ \\
\hline & $\begin{array}{l}\text { Wechsler Intelligences Scale for } \\
(\mathrm{SMP} / \mathrm{Mts})\end{array}$ & Children & $\begin{array}{l}\text { Very } \\
130\end{array}$ & Superior & $=$ \\
\hline & $\begin{array}{l}\text { Wechsler Intelligences Scale for } \\
\text { (SMA/MA) }\end{array}$ & Children & $\begin{array}{l}\text { Very } \\
130\end{array}$ & Superior & $=$ \\
\hline 5. & Intelligence Structure Test (SMA/MA) & & $\begin{array}{l}\text { Very } \\
130\end{array}$ & Superior & $=$ \\
\hline
\end{tabular}

Jadi, siswa SMA yang masuk dalam program akselerasi adalah siswa yang lulus dalam tes akademik, tes psikologi.

Struktur Program akselerasi pada kurikulum memuat mata pelajaran umum, muatan lokal, dan pengembangan diri yang mengacu pada Program Umum dan Program Ilmu Alam. Alokasi waktu juga mengikuti Program Ilmu Alam tetapi dikembangkan dengan tiga bentuk pengembangan yaitu Compacting (Pemampatan), Ascalating (Lompatan), dan Enricment (pengayaan). Diantara hasil pengembangan kurikulum antara lain, struktur kurikulum satu semester di kelas reguler dapat dilaksanakan dalam waktu periode 4 bulan untuk program akselerasi. Penanganan program akselerasi ini by class, tidak by subject. .

\footnotetext{
${ }^{7}$ Reni Akbar-Hawadi, Akselerasi: A-Z Informasi Program ................22

8 Dirjen Pendidikan Dasar dan Menengah Depdiknas, Pedoman Penyelenggaraan Program percepata Belajar SD, SMP dan SMA, (Jakarta: Depdiknas, 2003), 29
} 
Program akselerasi ini memuat kurikulum program umum (kelas $\mathrm{X}$ ) dan Program Ilmu Alam (kelas XI dan XII). satu jam pelajaran berdurasi 45 menit. Dengan kata lain kurikulum yang dirancang untuk program akselerasi adalah sama dengan program reguler. Dari segi mata pelajaran yang ditempuh, materi. Di sekolah yang kami teliti, tidak membuat kurikulum untuk program akselerasi secara spesifik. Yang berbeda hanya waktu yang ditempuh untuk menyelesaikan lebih singkat (dibuktikan dengan adanya kalender pendidikan tersendiri bagi kelas akselerasi), yang berpengaruh pada metode pemilihan materi yang esensial dengan kurang esensial.

Secara umum, dokumen 1 sudah baik. Baik dalam susunannya, maupun dalam pengembangannya. Terlihat pada pengembangan tujuan, pengembangan standar kompetensi maupun kompetensi dasar, dan lainnya. Selanjutnya, dalam dokumen II, yang terdiri dari silabus dan rencana pelaksanaan pembelajaran. Dari dokumentasi, kami mengetahui bahwa silabus yang digunakan mengacu pada departemen pendidikan agama. Silabus tersebut yang akan dikembangkan dalam rencana pelaksanaan pembelajaran. Ada beberapa upaya pengembangan kurikulum bidang studi pendidikan agama islam pada tahap perencanaan di kelas akselerasi yakni, Tahap perencanaan pengembangan kurikulum, hal ini dimulai dengan membentuk tim pengembang kurikulum. Tim pengembang kurikulum memiliki tugas, diantaranya menyusun dan mengembangkan kurikulum.

Pada dokumen II memuat Silabus dan RPP. Dari dokumendokumen tersebut, penulis menyimpulkan bahwa telah memiliki semua dokumen tersebut. Hal ini membuktikan bahwa telah melaksanakan KTSP. Dan dokumen tersebut telah disahkan oleh Dinas Pendidikan Kota Surabaya dan kepala Dinas Pendidikan Provinsi Jawa Timur.

Selanjutnya, upaya pengembangan kurikulum bidang studi pendidikan agama islam pada tahap implementasi di kelas akselerasi, terdiri dari 3 tahapan. Pertama, tahap perencanaan pembelajaran. Yang dilakukan dengan membuat RPP. Selain itu, guru bidang studi PAI juga mengikuti kegiatan Musyawarah Guru Mata Pelajaran (MGMP). Biasanya diadakan pada awal bulan, pada hari Sabtu. Pada saat MGMP, banyak hal yang dibahas, demi tercapainya pendidikan Islam yang bermutu dan aktual. Selain itu, pengembangkan materi pelajaran juga mengacu pada buku Kapita 
Selekta, Hadis Shahih Bukhori-Muslim, Qur'an tafsir, buku-buku paket yang ada, asbabun nuzul, cerita-cerita dan buku-buku yang lain. Selain itu, siswa diberi buku modul. Sehingga siswa mendapatkan Pendidikan Agama Islam cukup baik.

Ke dua, tahap pengembangan implementasi pembelajaran. Sesuai pengamatan kami, beliau telah melaksanakan keseluruhan kegiatan proses pembelajaran, mencapai target kompetensi yang dituangkan pada indikatorindikator, merencanakan metode yang digunakan untuk menyampaikan materi, mempersiapkan materi, merencanakan proses pembelajaran, buku penunjang, alat evaluasi yang digunakan dan lain-lain. Pada pengamatan kami, materinya yang disampaikan guru PAI sudah baik, walaupun antara RPP dan implementasinya ada sedikit perberbedaan.

Yang menarik adalah situasi dan kondisi di kelas, dimana Siswa dan siswi duduk tidak campur, melainkan saling bersisihan. Bagi siswi diharuskan memakai jilbab, meskipun banyak siswi memakai rok pendek. Dan kebanyakan dari mereka memakai mukena sebagai penutup kepala. Menurut peneliti hal itu cukup bagus, mengingat mereka belum menjadi pemakai jilbab yang istiqomah. Lalu siswa-siswi memulai pelajaran dengan berdoa, membaca fatihah dan membaca surat pendek secara bersama-sama. Kemudian Bapak Guru menerangkan materi pelajaran yang berjudul asbabun nuzul serta penjelasan mengenai surat yang dibacanya. Setelah itu Pak Guru menerangkan tentang pelajaran. Dari hasil wawancara dengan beberapa siswa, mereka senang dengan pengajarannya, karena ketika menerangkan diselingi humor, serta Bapak Gurunya sabar.

Selain itu, implementasi pembelajaran PAI juga didukung oleh pendukung lainnya, yang paling menonjol adalah adanya Seksi Kerohanian Islam (SKI). Dari hasil wawncara kami dengan salah satu siswa akselerasi, SKI ini mempunyai banyak kegiatan, diantaranya Bhirama (Bimbingan Rohani Lima) kegiatannya diadakan pada hari Jumat, Aladin (Ayo Teladani Nabi), Aladin ini punya tujuan untuk cinta pada Rosul Dilakukan pada waktu Maulid Nabi dengan mengadakan kuis, games dan lain-lain, RiskaReski yaitu kegiatan mengisi liburan dengan jalan-jalan dan membagikan makanan ke orang-orang di jalan. SMS Taujih, kita menyebarkan ayat-ayat alQur'an, Kebab (Belajar Bahasa Arab), secaramah agama yang dilaksanakan 2 
minggu sekali pada hari sabtu siang jam 12.00 sampe jam 15.00 di masjid sekolah secara bergantian.

Jadi, pada tahap ini banyak kegiatan yang dilakukan guru maupun siswa untuk mengembangkan pendidikan islam demi meningkatkan iman dan takwa pada Allah Swt. Kegiatan-kegiatan tersebut memperlihatkan bahwa siswa sangat kreatif, inovatif dalam mengadakan kegiatankegiatan islami, nama kegiatannya juga sangat mudah diingat dan familiar. Sehingga siswa SMA program akselerasi terlihat sangat sopan, religius dan berpengetahuan tinggi.

Ke tiga, tahap evaluasi pembelajaran, sistem Evaluasi yang digunakan adalah sistem evaluasi berbasis kelas. artinya evaluasi secara menyeluruh mulai dari proses awal sampai akhir. Evaluasi pembelajaran ini dilakukan untuk mengetahui kemampuan siswa atau kekurangan-kekurangan dalam proses pembelajaran. Guru mata pelajaran PAI menggunakan evaluasi yang sesuai dengan materi pelajaran. Misalnya tes tulis, tes praktik, penugasan dan lain-lain.

Sesuai dengan hasil observasi kami, pada saat UAS ujian praktek beliau juga mengadakan ujian paraktek sholat. Pada saat ujian praktek program akslerasi, beliau berdialog dengan siswa secara bersama-sama dan satu per satu untuk menyentuh hati siswa, sungguh luar biasa apa yang dilakukan beliau, karena tidak sedkit dari siswa maupun siswi yang menagis mendengar ceramah/pesan dari Guru Bidang Studi PAI. Kemudian siswa menghafalkan doa sholat mulai dengan iftitah sampai tahiyat akhir beserta terjemahnya. Lalu praktek sholat yang dilakukan secara bersama-sama. setelah itu siswa dipersilahkan untuk bertanya tentang hal-hal yang belum dimengerti dan diberi sedikit pencerahan.

Terlihat, bahawa guru mata pelajaran Pendidikan Agama Islam sudah berusaha mengembangkan evaluasi pembelelajaran pada program akslerasi dari aspek kognitif, afektif dan psikomotorik. Evaluasi yang digunakan adalah dengan penialain. Penilaian yang sering dilakukan adalah tes tulis, penugasan (bisa berupa tugas di rumah, klipping), ujian praktek.

Selanjutnya, upaya pengembangan Kurikulum Mata pelajaran Pendidikan Agama Islam pada Tahap Evaluasi di kelas Akselerasi SMA Negeri 5 Surabaya. Sesuai dengan wawancara yang kami lakukan, Evaluasi 
kurikulum dilakukan dengan diadakan satu kelanjutan yang diikuti oleh Bapak Ibu dari kelas aksel I sampai dengan kelas Aksel II. Tujuannya untuk mengetahui perkembangan psikisnya, perkembangan akademik peserta didik. Jadi guru mulai dari kelas aksel I sampai kelas Aksel II gurunya tetap. Perkembangan tersebut dilaporkan ke Kepala Sekolah, dengan mengevaluasi kekurangan dan kelebihannya.

\section{Kesimpulan}

Pelaksanaan program akselerasi di SMA Negeri 5 Surabaya ini telah berjalan sejak tahun 2006. Program akselerasi di sekolah ini ditempuh dalam 2 tahun. Dan dikhususkan bagi siswa IPA karena memang banyak dari mereka (jurusan IPA) yang mempunyai kemampuan IQ diatas rata-rata. Sekolah telah melakukan beberapa persiapan untuk program akslerasi, diantaranya dalam segi standart isi, standart proses, standar pendidik dan tenaga kependidikan, standart kompetensi lulusan, standar sarana dan prasarana, standar pengelolaan, standar pembiayaan dan standar penilaian pendidikan.

SMA Negeri 5 Surabaya telah melakukan pengembangan kurikulum mata pelajaran Pendidikan Agama Islam pada program akslerasi. Mulai tahap perencanaan kurikulum, tahap implementasi kurikulum (perencanaan pembelajaran, implementasi pembelajaran dan evaluasi pembelajaran) dan evaluasi kurikulum. Dalam tahap perencanaan kurikulum, SMA Negeri 5 Surabaya telah membentuk tim pengembang kurikulum dan menyusun dokumen I.

Pada tahap imlementasi kurikulum, guru telah membuat silabus dan RPP serta mengikuti kegiatan MGMP setiap satu bulan sekali, beliau juga menyiapkan materi dengan baik dan membuat suasana kelas menjadi islami, mengajarkan mata pelajaran dari berbagai buku, tidak hanya berpatokan pada buku paket saja. Dan pada tahap implementasi pembelajaran, siswa banyak yang memperhatikan. Walaupun guru PAI tidak banyak menggunakan strategi pembelajaran yang inovatif, namun dengan pembelajaran yang sederhana dan menyentuh hati siswa, pembelajaran menjadi kondusif. Beliau juga telah milih materi yang esensi dan materi yang kurang esensi. 
Sekolah ini juga ada organisasi SKI yang mempunyai peran cukup penting dalam menyelenggarakan suasana sekolah menjadi lebih islami, karena SKI ini merupakan bagian dari OSIS. SKI mempunyai banyak kegiatan, misalnya pengajian, aladin, bhirama, riska-reska, panji, kilaska, mengisi acara pada hasi besar islam dan masih banyak yang lainnya. Sehingga siswa SMA Negeri 5 Surabaya terlihat sangat sopan, religius dan berpengetahuan tinggi.

Pada tahap evaluasi pembelajaran, guru tidak hanya menggunakan tes tulis, namun juga menggunakan non tes. Tes tulis, biasanya digunakan pada saat ulangan harian, ulangan tengah semester dan ulangan akhir semester. Dan non tes digunakan pada ujian praktek ataupun tugas.

Pada tahap evaluasi kurikulum, SMA Negeri 5 Surabaya langsung melaoprkan hasil laporannya kepada Depdiknas Kota Surabaya, dan mereka diberi feed back oleh pengawas satuan pendidikan. Namun problem yang dihadapi dalam tahap ini adalah tidak adanya monitoring dan evaluasi dari kepada sekolah terlebih dahulu, sebelum dilakukan pelaporan kepada Depdiknas Kota Surabaya. SMA Negeri 5 Surabaya tidak menerima feed back langsung dari Depdiknas Kota Surabaya, karena Depdiknas Kota Surabaya memberikan workshop/pengarahan kepada beberapa sekolah secar langsung. 


\section{Daftar Pustaka}

Dirjen Pendidikan Dasar dan Menengah Depdiknas, Pedoman Penyelenggaraan Program percepata Belajar SD, SMP dan SMA, (Jakarta: Depdiknas, 2003).

Hendyat Soetopo dan Wasty Soemanto, Pembinaan dan Pengembangan Kurikulum, (Jakarta: Bumi Aksara, 1993).

Ngalim Purwanto, Psikologi Pendidikan, (Bandung: Remaja Rosdakarya, 1992).

Reni Akbar-Hawadi, Akselerasi: A-Z Informasi Program Percepatan Belajar, (Jakarta:

Grasindo Widiasarana Indonesia, 2004).

Reni Hawadi Akbara, Keberbakatan Intelektual, (Jakarta: Grasindo: 2001).

S. Nasution, Asas-Asas Kurikulum, (Bandung: Jemmars, 1986).

Sutratinah Tirtonegoro, Anak Supernormal dan Program Pendidikannya, (Yogyakarta: Bumi Aksara, 2001).

Syaiful Bahri Djamarah, Psikologi Belajar, (Jakarta: Rineka Cipta, 2008).

Undang-Undang No. 20 Tahun 2003 tentang Sistem Pendidikan Nasional. 